\title{
Physiologically Based Pharmacokinetics of Dexamethasone in Rats ${ }^{\text {霖 }}$
}

\author{
Dawei Song, ${ }^{1}$ Le Sun, ${ }^{1}$ Debra C. DuBois, Richard R. Almon, Shengnan Meng, and William J. Jusko \\ Departments of Pharmaceutical Sciences (D.S., L.S., D.C.D., R.R.A., W.J.J.) and Biological Sciences (D.C.D., R.R.A.), School of \\ Pharmacy and Pharmaceutical Sciences, State University of New York at Buffalo, Buffalo, New York; and Department of \\ Pharmaceutics, School of Pharmacy, China Medical University, Shenyang, China (S.M.)
}

Received February 20, 2020; accepted June 9, 2020

\begin{abstract}
Blood and multitissue concentration-time profiles for dexamethasone (DEX), a synthetic corticosteroid, were measured in male rats after subcutaneous bolus and infusion dosing. A physiologically based pharmacokinetics (PBPK) model was applied for 12 measured tissues. Tissue partition coefficients $\left(K_{p}\right)$ and metabolic clearance were assessed from infusion studies. Blood cell to plasma partitioning $(0.664)$ and plasma free fraction $(0.175)$ for DEX were found to be moderate. DEX was extensively partitioned into liver $\left(K_{p}=6.76\right)$, whereas the calculated $K_{p}$ values of most tissues ranged between 0.1 and 1.5. Despite the moderate lipophilicity of DEX $(\log P=1.8)$, adipose exhibited very limited distribution $\left(K_{p}=0.17\right)$. Presumably due to P-glycoprotein-mediated efflux, DEX concentrations were very low in brain compared with its expected high permeability. Infusion studies yielded $K_{p}$ values from male and female rats at steady state that were similar. In silico $K_{p}$ values calculated for
\end{abstract}

\section{Introduction}

Corticosteroids (CSs), first synthesized in the 1950s, are synthetic analogs of the endogenous glucocorticoid (GC) cortisol. In addition to rapid nongenomic effects, GCs (and CSs) bind to the ubiquitously expressed glucocorticoid receptors in the cytoplasm of various tissues (Oakley and Cidlowski, 2011). The GC-glucocorticoid receptor complexes then translocate into the nucleus, influencing downstream gene expression resulting in numerous biologic effects in multiple tissues (Cato et al., 2002; Losel and Wehling, 2003; Baschant et al., 2012). The CSs have strong immunosuppressive and anti-inflammatory properties, which provide the foundation for their wide application in conditions including organ transplants, rheumatoid arthritis, some lymphomas, and many others (Rhen and Cidlowski, 2005; Kadmiel and Cidlowski, 2013). Furthermore, CSs are also used in non-immune-related conditions, such as hormone replacement therapy for Addison's disease (Napier and Pearce, 2014) and promoting lung maturation to prevent respiratory distress syndrome in preterm births (Kadmiel and Cidlowski, 2013). However, high doses or chronic use of CSs can magnify normal

This work was supported by National Institutes of Health National Institute of General Medical Sciences, [Grant GM24211 and Grant GM131800]. This work was also supported by the National Natural Science Foundation of China (No. 81603055).

${ }^{1}$ D.S. and L.S. have contributed equally to these studies.

https://doi.org/10.1124/dmd.120.091017.

S This article has supplemental material available at dmd.aspetjournals.org. different tissues by using GastroPlus software were similar to in vivo values except for adipose and liver. Glucocorticoid receptors are found in diverse tissues, and these PBPK modeling results may help provide exposure profiles driving pharmacodynamic effects of DEX.

\section{SIGNIFICANCE STATEMENT}

Our physiologically based pharmacokinetics model describes the experimentally determined tissue and plasma dexamethasone (DEX) pharmacokinetics (PK) profiles in rats reasonably well. This model can serve for further investigation of DEX tissue distribution in rats as the PK driving force for PD effects in different tissues. No major sex differences were found for DEX tissue distribution. Knowledge gained in this study may be translatable to higher-order species including humans.

ABBREVIATIONS: B/P, blood to plasma ratio; CS, corticosteroid; DEX, dexamethasone; GC, glucocorticoid; IS, internal standard; P-gp, P-glycoprotein; PBPK, physiologically based pharmacokinetics; PK, pharmacokinetics; RBC, red blood cell. 
relationships between pharmacological and toxicological effects and drug concentrations at the site of action.

Previous studies showed higher clearances in male rats compared with females based on plasma profiles for both DEX and methylprednisolone (Song et al., 2018; Ayyar et al., 2019a). Whether there exist sex differences in DEX tissue distribution has not been studied. Therefore, the purposes of the current study were the following: 1) Thorough investigation and description of multiorgan PK profiles of DEX in rats to seek a better understanding of determinants for DEX whole-body PK. 2) Comparison of tissue partition coefficients between females and males to augment previous PK studies of DEX in relation to sex in rats. 3) Obtaining a data base for possible scaling the PBPK of DEX to other species.

\section{Methods}

Chemicals and Reagents. Pharmaceutical-grade dexamethasone sodium phosphate solution was purchased from Bimeda Pharmaceuticals (Dublin, Ireland). Dexamethasone-D5 (internal standard [IS], purity $>98 \%$ ) was obtained from Toronto Research Chemicals (Toronto, ON, Canada). Dexamethasone (purity $>98 \%$ ) was purchased from Sigma-Aldrich (St Louis, MO). High-performance liquid chromatography-grade methanol, acetonitrile, and phosphoric acid were obtained from Fisher Scientific (Pittsburgh, PA). Milli-Q water was used in the study (Millipore Corporation, Bedford, MA). Subcutaneously implanted osmotic minipumps (Model 2ML1) were purchased from Alzet (Palo Alto, CA).

Animals. Healthy male and female Wistar Rats were purchased from Envigo (Indianapolis, IN). Rats had free access to rat chow and drinking water. Rats were housed two per cage under controlled temperature and humidity with 12 hour:12 hour dark-light cycles. The study protocols adhered to the Principles of Laboratory Animal Care (National Institutes of Health publication 85-23, revised 1985) and were approved by the University at Buffalo Institutional Animal Care and Use Committee.

DEX Pharmacokinetics. Three male rats, weighing around $310 \mathrm{~g}$, and three female rats of about $280 \mathrm{~g}$ were first studied. DEX was infused subcutaneously through Alzet osmotic pumps at concentrations of 3 and $1.45 \mathrm{mg} / \mathrm{ml}$ at rates of $10 \mu \mathrm{l} / \mathrm{h}$ for 24 hours to achieve similar steady-state plasma drug concentrations. Animals were then sacrificed, and plasma, blood (female only), and harvested tissues were processed for liquid chromatography-mass spectrometry analysis of drug concentrations. A second group of male rats received a single s.c. dose of $2.25 \mathrm{mg} / \mathrm{kg}$ DEX. These rats were sacrificed at nine time points ( $N=3$ per time point): 0.25 , $0.5,1,2,4,6,8,12$, and 24 hours. In all studies, whole blood and tissues were harvested, including heart, liver, spleen, lung, kidney, muscle (gastrocnemius), skin, abdominal fat, brain, bone (tibia), and intestine. Plasma was obtained by centrifugation $\left(2000 \mathrm{~g}, 4^{\circ} \mathrm{C}, 15\right.$ minutes $)$ using EDTA as anticoagulant (final concentration $4 \mathrm{mmol} / \mathrm{l}$ ). Collected tissues were frozen in liquid nitrogen, ground to a fine powder under liquid nitrogen, and stored at $-80^{\circ} \mathrm{C}$ until extraction.

In Vitro Blood Partitioning. Fresh blood was collected from an untreated female Wistar rat with EDTA as anticoagulant. Part of the collected blood was centrifuged for plasma $\left(2000 \mathrm{~g}, 4^{\circ} \mathrm{C}, 15\right.$ minutes $)$. Methanolic stocks of DEX were spiked into blank blood to yield approximately 1500,500 , and $5 \mathrm{ng} / \mathrm{ml}$ concentrations, and DEX was also added into blank plasma to obtain $1500 \mathrm{ng} / \mathrm{ml}$ samples. Then $150 \mu \mathrm{l}$ aliquots of these spiked blood and plasma samples were immediately frozen for DEX quantification. The remaining samples were incubated for 60 minutes at $37^{\circ} \mathrm{C}$. Immediately after incubation, $150 \mu \mathrm{l}$ of all samples was transferred into microfuge tubes and frozen. These provided total DEX concentrations after incubation to assess possible DEX degradation in either blood or plasma during incubation. The remaining blood samples after incubation were spun to obtain plasma (2000g, $4^{\circ} \mathrm{C}, 15$ minutes). Plasma samples were frozen and stored at $-20^{\circ} \mathrm{C}$ for the following analysis.

Sample Preparation and DEX Liquid Chromatography-Mass Spectrometry Assay. Detailed sample preparation for plasma and tissues was reported previously (Li et al., 2017; Ayyar et al., 2019b). Briefly, $100 \mu \mathrm{l} 4 \%$ phosphoric acid was added to the same volume of plasma and then spiked with $10 \mu \mathrm{l}$ of IS ( $\mathrm{D}_{5}$-DEX) working solution. After vortexing and centrifugation at $13,000 \mathrm{~g}$ for 10 minutes at $10^{\circ} \mathrm{C}$, supernatants were

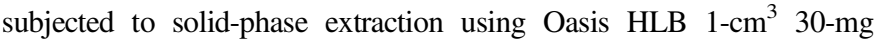
cartridges (Waters Corp., Milford, MA). Homogenates of tissues were prepared and drug extracted with methanol. In brief, powdered tissue was homogenized in PBS at a 6-fold dilution using a PRO-200 BIO-GEN homogenizer (ProScientific, Oxford, CT) at maximum speed setting five for 30 seconds. Experimental homogenates totaling $100 \mathrm{ul}$ was added into $990 \mu \mathrm{l}$ methanol and then spiked with $10 \mu \mathrm{l}$ of IS stocks. After vortexing and centrifugation $\left(4^{\circ} \mathrm{C}\right.$ at $14,000 \mathrm{~g}$ for 20 minutes), the supernatants were transferred to glass tubes and dried under nitrogen flow. The dried residue was reconstituted with $50 \mu \mathrm{l}$ methanol, vortexed twice for 30 seconds, and diluted with water $(450 \mu \mathrm{l})$. Then samples $(450 \mu \mathrm{l})$ were mixed with equal volumes of $4 \%$ phosphoric acid in microfuge tubes and underwent solidphase extraction using Oasis Prime HLB $1-\mathrm{cm}^{3} 30-\mathrm{mg}$ cartridges. Blood samples without dilution were directly homogenized for 30 seconds at maximum speed and then were treated the same as tissue samples. The reconstitution solution for dried residue was $200 \mu \mathrm{l}$ of acetonitrile/water $(30: 70, \mathrm{v} / \mathrm{v})$. The mobile phase consisted of one eluent (acetonitrile/water $(5: 95 \mathrm{v} / \mathrm{v})$ containing $0.1 \%$ formic acid) and the second (acetonitrile/water $(95: 5 \mathrm{v} / \mathrm{v})$ containing $0.1 \%$ formic acid). The lower limit of quantification of DEX was $0.2 \mathrm{ng} / \mathrm{ml}$ (or $\mathrm{ng} / \mathrm{g}$ ) in plasma, blood, and tissues. Based on extensive data obtained over decades, corticosteroids in various matrices and during freeze-thaw cycles are known to be stable and were not investigated here (Volin, 1995).

Data Analysis. Blood to plasma ratios at each concentration was calculated by the following equation:

$$
B / P=C_{\text {Blood }} / C_{\text {Plasma }} \text {. }
$$

The DEX concentrations for this calculation were obtained either from the in vitro blood partitioning study or the subcutaneous infusion study in female rats.

Tissue DEX concentration data were corrected for residual blood as follows:

$$
C_{t}=\frac{C_{t(\text { meas })} \cdot V_{\text {meas }}-C_{p l} \cdot V_{\text {meas }} \cdot\left(V_{\text {vasc }} / V_{t}\right)}{V_{\text {meas }}-\left[V_{\text {meas }} \cdot\left(V_{\text {vasc }} / V_{t}\right)\right]},
$$

where $C_{t}$ and $C_{t(\text { meas })}$ are the corrected and measured tissue concentrations, $C_{p l}$ is the measured plasma concentration, $V_{\text {meas }}$ is the measured or estimated volumes of collected tissues, $V_{\text {vasc }}$ is the tissue vascular volume, and $V_{t}$ is the tissue volume. Literature-reported values were used to correct tissue DEX concentrations (Bernareggi and Rowland, 1991).

Tissue partition coefficients $K_{p}$ were obtained using several methods:

1) Calculation from steady-state data from the infusion study.

$$
\begin{aligned}
& K_{P, i}=\frac{C_{i, s s}}{C_{p, s s}} \text { (for noneliminating organ), } \\
& K_{P, \text { hep }}=\frac{C_{\text {hep }, s s}}{C_{\text {plasma }, s s}} \cdot\left(\frac{Q_{\text {hep }}+f_{u, p} \cdot C L_{u, i n t}}{Q_{\text {hep }}}\right)
\end{aligned}
$$

(For liver as eliminating organ),

where $C$ is the measured concentration, $Q_{\text {hep }}$ is the hepatic blood flow, $C L_{u, i n t}$ is the intrinsic clearance, and subscripts indicate the tissue $(i)$, plasma $(p)$, and steady state (ss). 
2) Parameter estimation through PBPK modeling as described in detail below.

3) In silico $K_{p}$ prediction using GastroPlus PBPK Simulator (version 9.6.2, Simulations Plus Inc., Lancaster, CA). As described previously (Ayyar et al., 2019b), published methods (Poulin and Theil, 2002; Berezhkovskiy, 2004; Rodgers and Rowland, 2006) for neutral compounds were used and are listed as Methods 1-3.

PBPK Model. Figure 1 shows the proposed PBPK model structure for DEX. Arterial and venous blood were modeled as two separate compartments, and the measured blood concentrations were treated as arterial blood concentrations. This model consisted of 12 tissues, including liver, kidney, lung, heart, spleen, intestine, muscle, fat, bone, skin, brain, and remainder. All organs except those mentioned were lumped into the remainder compartment. The blood flow for each organ except lung originates as arterial blood, then perfuses each organ and converges as venous blood. In lung, blood flow is reversed. For intestine and spleen, after leaving the tissues, blood goes through the liver via the hepatic portal vein and mixes with liver artery flow upon entry into venous blood. The elimination pathway for DEX is predominantly hepatic metabolism through CYP3A pathways in rodents (Tomlinson et al., 1997), and only free hepatic DEX is assumed to diffuse through cellular membranes and is subject to metabolism. The rat brain $K_{p}$ was assumed as 1.20 as measured in P-glycoprotein (P-gp) knockout mice (Uchida et al., 2011), and bidirectional apparent permeability coefficients that involve both passive diffusion and active efflux were employed. All physiologic parameter definitions and values are listed in Table 1. The plasma protein binding of DEX was determined previously (Ayyar et al., 2019b) as 0.175 plasma free fraction $\left(f_{u, p}\right)$ and used to calculate DEX free fraction in liver $\left(f_{u, L}\right)$ with the following equation:

$$
f_{u, L}=\frac{f_{u, p}}{K_{p, L}}
$$

where $K_{p, L}$ is the plasma partition coefficient for liver.

The differential equations for the PBPK model are as follows.

Venous Blood.

$$
\begin{aligned}
V_{V} \cdot \frac{d C_{V}}{d t}= & \text { Input }+R_{B} \cdot\left(Q_{\text {liver }} \cdot \frac{C_{\text {liver }}}{K_{p, \text { liver }}}+Q_{\text {kidney }} \cdot \frac{C_{\text {kidney }}}{K_{p, \text { kidney }}}\right. \\
& +Q_{\text {heart }} \cdot \frac{C_{\text {heart }}}{K_{p, \text { heart }}}+Q_{\text {muscle }} \cdot \frac{C_{\text {muscle }}}{K_{p, \text { muscle }}}+Q_{\text {fat }} \cdot \frac{C_{\text {fat }}}{K_{p, \text { fat }}} \\
& \left.+Q_{\text {bone }} \cdot \frac{C_{\text {bone }}}{K_{p, \text { bone }}}+Q_{\text {skin }} \cdot \frac{C_{\text {skin }}}{K_{p, \text { skin }}}+Q_{\text {rest }} \cdot \frac{C_{\text {rest }}}{K_{p, \text { rest }}}\right) \\
& +Q_{\text {brain }} \cdot C_{\text {brain, cap }}-Q_{\text {lung }} \cdot C_{V} \\
& Q_{\text {liver }}=Q_{\text {liver, art }}+Q_{\text {intestine }}+Q_{\text {spleen }}
\end{aligned}
$$

Lung.

$$
V_{\text {lung }} \cdot \frac{d C_{\text {lung }}}{d t}=Q_{\text {lung }} \cdot C_{V}-Q_{\text {lung }} \cdot \frac{R_{B} \cdot C_{\text {lung }}}{K_{p, \text { lung }}}
$$

Arterial Blood.

$$
\begin{aligned}
V_{A} \cdot \frac{d C_{A}}{d t}= & Q_{\text {lung }} \cdot \frac{R_{B} \cdot C_{\text {lung }}}{K_{p, \text { lung }}}-\left(Q_{\text {liver, art }}+Q_{\text {kidney }}+Q_{\text {heart }}+Q_{\text {muscle }}\right. \\
& +Q_{\text {intestine }}+Q_{\text {spleen }}+Q_{\text {fat }}+Q_{\text {bone }}+Q_{\text {skin }}+Q_{\text {brain }} \\
& \left.+Q_{\text {rest }}\right) \cdot C_{A}
\end{aligned}
$$

$$
V_{\text {spleen }} \cdot \frac{d C_{\text {spleen }}}{d t}=Q_{\text {spleen }} \cdot\left(C_{A}-\frac{R_{B} \cdot C_{\text {spleen }}}{K_{p, \text { spleen }}}\right)
$$

Intestine.

$$
V_{\text {intestine }} \cdot \frac{d C_{\text {intestine }}}{d t}=Q_{\text {intestine }} \cdot\left(C_{A}-\frac{R_{B} \cdot C_{\text {intestine }}}{K_{p, \text { intestine }}}\right)
$$

Liver.

$$
\begin{array}{r}
V_{\text {liver }} \cdot \frac{d C_{\text {liver }}}{d t}=Q_{\text {liver, art }} \cdot C_{A}+Q_{\text {spleen }} \cdot \frac{R_{B} \cdot C_{\text {spleen }}}{K_{p, \text { spleen }}}+Q_{\text {intestine }} \\
\cdot \frac{R_{B} \cdot C_{\text {intestine }}}{K_{p, \text { intestine }}}-Q_{\text {liver }} \cdot \frac{R_{B} \cdot C_{\text {liver }}}{K_{p, \text { liver }}}-C L_{u, \text { int }} \cdot C_{\text {liver }} \cdot f_{u, L}
\end{array}
$$

Kidney.

$$
V_{\text {kidney }} \cdot \frac{d C_{\text {kidney }}}{d t}=Q_{\text {kidney }} \cdot\left(C_{A}-\frac{R_{B} \cdot C_{\text {kidney }}}{K_{p, \text { kidney }}}\right)
$$

Heart.

$$
V_{\text {heart }} \cdot \frac{d C_{\text {heart }}}{d t}=Q_{\text {heart }} \cdot\left(C_{A}-\frac{R_{B} \cdot C_{\text {heart }}}{K_{p, \text { heart }}}\right)
$$

Adipose.

$$
V_{f a t} \cdot \frac{d C_{f a t}}{d t}=Q_{f a t} \cdot\left(C_{A}-\frac{R_{B} \cdot C_{f a t}}{K_{p, f a t}}\right)
$$

Muscle.

$$
V_{\text {muscle }} \cdot \frac{d C_{\text {muscle }}}{d t}=Q_{\text {muscle }} \cdot\left(C_{A}-\frac{R_{B} \cdot C_{\text {muscle }}}{K_{p, \text { muscle }}}\right)
$$

Bone.

$$
V_{\text {bone }} \cdot \frac{d C_{\text {bone }}}{d t}=Q_{\text {bone }} \cdot\left(C_{A}-\frac{R_{B} \cdot C_{\text {bone }}}{K_{p, \text { bone }}}\right)
$$

Skin.

$$
V_{s k i n} \cdot \frac{d C_{s k i n}}{d t}=Q_{s k i n} \cdot\left(C_{A}-\frac{R_{B} \cdot C_{s k i n}}{K_{p, s k i n}}\right)
$$

Remainder.

$$
V_{\text {rest }} \cdot \frac{d C_{\text {rest }}}{d t}=Q_{\text {rest }} \cdot\left(C_{A}-\frac{R_{B} \cdot C_{\text {rest }}}{K_{p, r e s t}}\right)
$$

\section{Brain Capillary.}

$$
\begin{aligned}
V_{\text {brain, cap }} \cdot \frac{d C_{\text {brain, cap }}}{d t}= & Q_{\text {brain }} \cdot\left(C_{A}-C_{\text {brain, cap }}\right)-P S_{L-A L} \cdot f_{u, p} \\
& \cdot \frac{C_{\text {brain, cap }}}{R_{B}}+P S_{A L-L} \cdot C_{\text {brain, }} \cdot f_{u, p} / K_{p, \text { brain }}
\end{aligned}
$$

Brain.

$$
\begin{array}{r}
V_{\text {brain },} \cdot \frac{d C_{\text {brain }}}{d t}=P S_{L-A L} \cdot f_{u, p} \cdot \frac{C_{\text {brain, cap }}}{R_{B}}-P S_{A L-L} \cdot C_{\text {brain }} \\
\cdot f_{u, p} / K_{p, b r a i n}
\end{array}
$$

In these equations, $V_{i}, Q_{i}, C_{i}$, and $K_{p, i}$ are volume, blood flow, DEX concentration and partition coefficient for tissue $i ; R_{B}$ is blood to plasma ratio; $C L_{u, i n t}$ is the unbound intrinsic clearance in liver; and $P S_{L-A L}$ and

Spleen. 


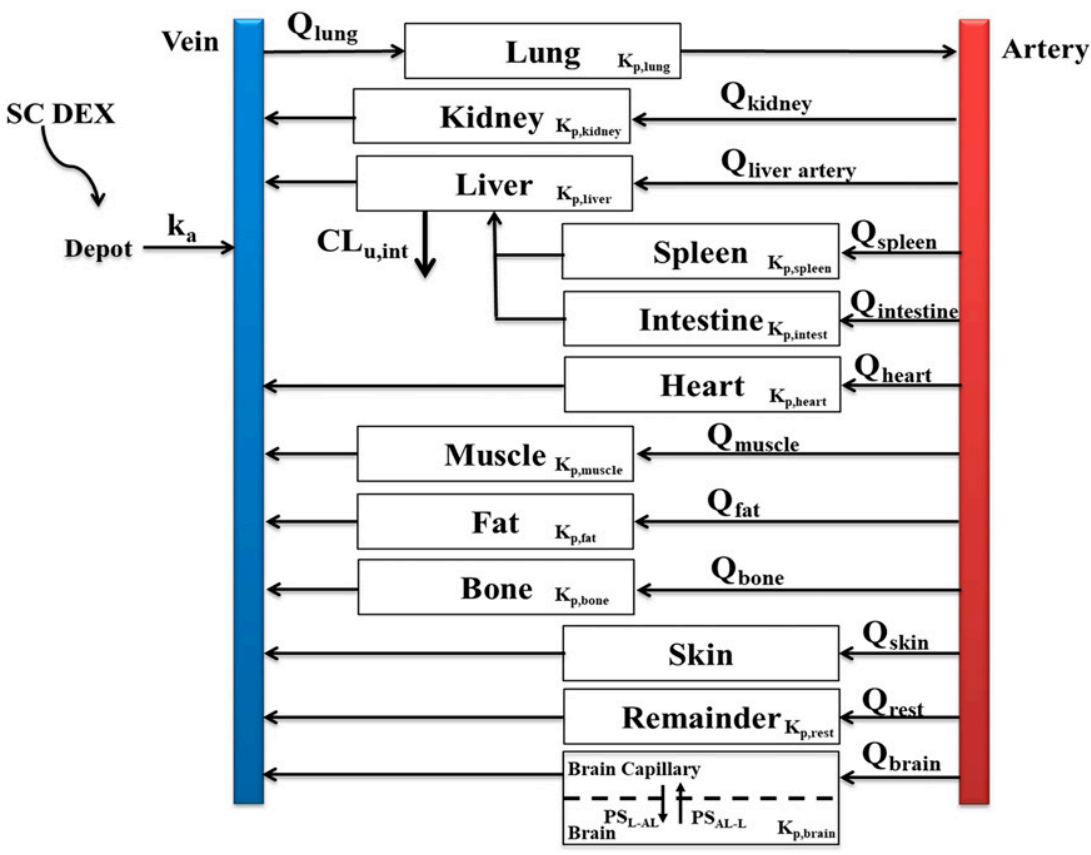

Fig. 1. Schematic of the full PBPK model structure for DEX. Parameters and symbols are defined in the text and tables. Lines with arrows indicate blood flows and drug transport. Each box represents one tissue compartment as indicated by the label.

$P S_{A L-L}$ are permeability coefficients for luminal-abluminal and abluminal-luminal in brain.

The dosing input for subcutaneous administration is as follows:

$$
\text { Input }=k a \cdot \text { Dose } \cdot F \text {. }
$$

The initial conditions for all differential equations are equal to 0 . Bioavailability $(F)$ was fixed to 0.86 according to previous literature (Samtani and Jusko, 2005).

After model fitting, $K_{p}$ values for female rats obtained from the infusion study and physiologic parameters scaled by body weight (exponents for volume and blood flow: 1 and 0.75 ) were used to simulate the plasma PK profile after the $2.25 \mathrm{mg} / \mathrm{kg}$ s.c. single dose (mean body weight $112 \mathrm{~g}$ ). This simulated profile was overlaid with our observed data for female rats (Li et al., 2017).

TABLE 1

Physiologic parameters of tissues in a $310 \mathrm{~g}$ male rat

\begin{tabular}{lcc}
\hline Tissue & $\begin{array}{c}\text { Volume } \\
(V) \mathrm{ml}\end{array}$ & $\begin{array}{c}\text { Blood } \\
\text { flow }(Q) \\
\mathrm{ml} / \mathrm{h}\end{array}$ \\
\hline Lung & $1.11^{a}$ & $5779^{b}$ \\
Brain & $1.51^{a}$ & $128^{b}$ \\
Heart & $0.92^{a}$ & $297^{b}$ \\
Intestine & $8.61^{b}$ & $1091^{b}$ \\
Spleen & $0.42^{a}$ & $351^{b}$ \\
Kidney & $1.82^{a}$ & $716^{b}$ \\
Muscle & $134.5^{b}$ & $1815^{b}$ \\
Liver artery & $11.3^{a}$ & $41.4^{b}$ \\
Skin & $55.1^{b}$ & $392^{b}$ \\
Bone & $22.8^{b}$ & $120^{b}$ \\
Fat & $36.4^{b}$ & $440^{b}$ \\
Arterial & $6.08^{b}$ & $5779^{b}$ \\
$\quad$ blood & & \\
Venous & $12.2^{b}$ & $5779^{b}$ \\
$\quad$ blood & $17.2^{c}$ & $387^{c}$ \\
\hline
\end{tabular}

${ }^{a}$ Experiment value.

${ }^{b}$ From Shah and Betts (2012)

${ }^{c}$ Calculated value 1) assuming $1 \mathrm{ng} / \mathrm{ml}$ tissue density, volume for rest of body = body weight - summation of volume for listed tissues; 2) blood flow for rest of body = cardiac output summation of blood flow for listed tissues).
Model Fitting. The tissue partition coefficients for all harvested tissues $\left(K_{p}\right)$, two brain permeability coefficients $(P S)$, subcutaneous absorption rate constant $\left(k_{a}\right)$, and hepatic intrinsic clearance $\left(C L_{u, i n t}\right)$ were estimated. All fittings and simulations were implemented using ADAPT version 5 (Biomedical Simulations Resource, University of Southern California, Los Angeles, CA) using maximum likelihood estimation. The ADAPT code for modeling our data is provided in the Supplemental Materials. The model was evaluated based on Akaike information criterion, visual inspection of the fitted profiles, and CV\% of parameter estimates. The variance model was as follows:

$$
V_{i}=\left(\sigma_{1}+\sigma_{2} \cdot Y_{i}\right)^{2}
$$

where $V_{i}$ represents the variance of the $i$ th data point, $Y_{i}$ is the $i$ th model prediction, and $\sigma_{1}$ and $\sigma_{2}$ are variance model parameters. All figures were created using GraphPad Prism version 7.04 (GraphPad Software, La Jolla, CA).

\section{Results}

Blood Cell Partitioning. As shown in Figure 2, the DEX blood to plasma ratios $(B / P)$ based on female rat subcutaneous infusion and in vitro partitioning were calculated to be 0.727 (S.D. $=0.07, n=3$ ) and 0.723 (S.D. $=0.08, n=3$ ) with combined $B / P$ value of 0.725 (S.D. $=$ $0.08, n=6)$. The lower DEX concentration in blood compared with plasma appears to be due to protein binding ( $82.5 \%$, to be shown). The average $B / P$ obtained from the male rat subcutaneous bolus study was 0.664 , which was slightly smaller than the female.

Whole-Body Pharmacokinetics of DEX. Figure 3 shows measured and fitted time-course PK profiles of DEX after single subcutaneous dosing in blood and tissues. Generally, the current model captures the tissue PK well with slight overestimation for muscle. The delayed peak DEX concentration in brain necessitated the incorporation of permeability-limited entry and transporter-mediated efflux with two different permeability coefficients.

The DEX $K_{p}$ for each tissue as well as other relevant parameters were obtained from PBPK modeling of male subcutaneous bolus data (Table 2). The intercept and slope for the variance model were 1.39 
A

\section{DEX Blood Partitioning in Male Rat}

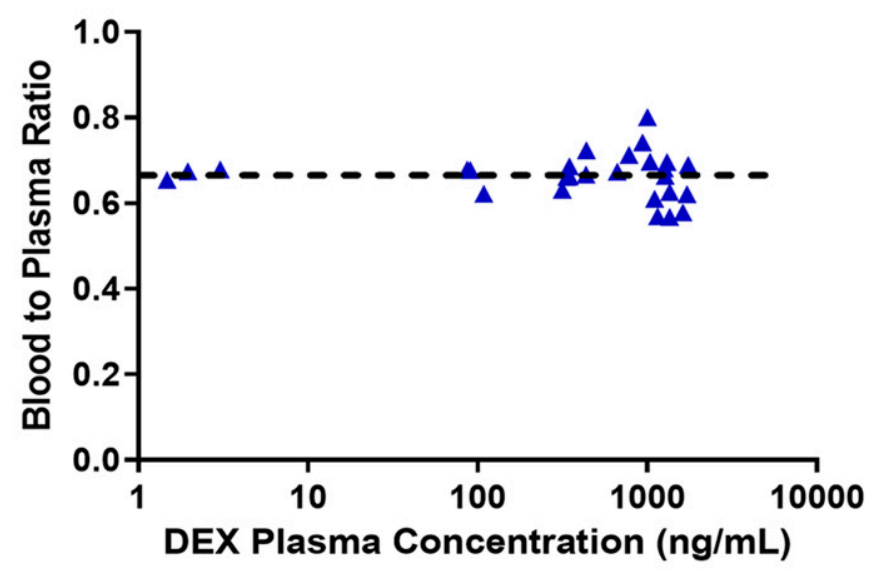

B

DEX Blood Partitioning in Female Rat

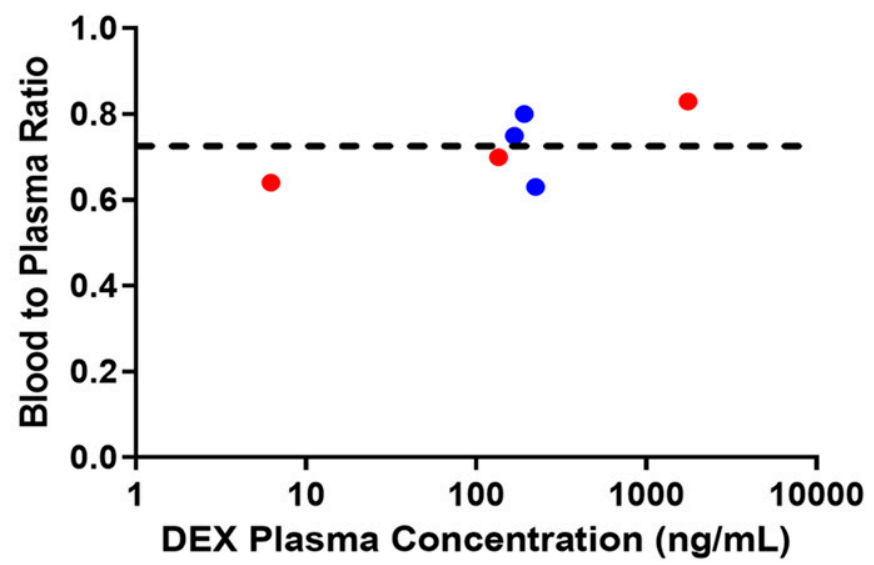

Fig. 2. DEX blood to plasma ratio vs. corresponding plasma concentrations in male (A) and female (B) rats. Blue triangles are ratios calculated from the subcutaneous bolus study in male rats. Red dots indicate the ratio calculated from the in vitro blood cell partitioning study, and blue dots are ratios calculated from the subcutaneous infusion study in female rats. The dashed line shows the mean value of all points.

and 0.22. All parameters were estimated with good precision with $\mathrm{CV}$ $\%<50 \%$. The $K_{p}$ values for most tissues are around 1 . However, the $K_{p}$ values are 6.76 for liver and 1.51 for kidney, indicating extensive partitioning of DEX in liver and above-average partitioning in kidney. In adipose tissue, the $K_{p}$ value obtained (0.15) was surprisingly low. Our model-fitted $K_{p}$ values were very close to those calculated from our steady-state infusion study in male rats, as shown in Table 2. The two estimated permeability coefficients showed a large difference (1.46 vs. 24.3), which indicates significant contribution of active efflux from the brain.

Comparing results from males and females in the infusion study, $K_{p}$ values were similar except for modest differences for lung, intestine, kidney, liver, and possibly fat. Lung had a greater $K_{p}$ in females than males $(0.69 \pm 0.09$ vs. $0.50 \pm 0.06)$, and males had greater $K_{p}$ values (e.g., $5.06 \pm 0.56$ vs. $4.10 \pm 0.56$ in liver) for the other four tissues. The measured liver $K_{p}$ for both sexes from the infusion studies were 4.55 (male) and 3.76 (female) without correction for metabolism (eq. 3). As expected, the corrected $K_{p}$ values increased to 5.06 and 4.10. As illustrated in Table 2, the in vivo $K_{p}$ values for most tissues showed distinct differences from in silico values obtained using the three calculation methods. Figure 4 shows a simulated DEX plasma PK profile in female rats, illustrating that model predictions are in good agreement with measured plasma concentrations except for the last time point.

Rat hematocrit (HCT) values were reported as 0.40 (male) and 0.37 (female) (Probst et al., 2006), and we obtained mean DEX B/P values of 0.664 (male) and 0.725 (female). If we assume that only free DEX in plasma partitions into blood cells and red blood cells (RBCs) are the predominant cells in blood, $B / P$ could be obtained from the following equation:

$$
\begin{gathered}
\frac{C_{\text {Blood }}}{C_{\text {Plasma }}}=\frac{C_{\text {Plasma }} \cdot f_{u, p} \cdot V_{\text {Blood }} \cdot H C T+C_{\text {Plasma }} \cdot V_{\text {Blood }} \cdot(1-H C T)}{V_{\text {Blood }} \cdot C_{\text {Plasma }}} \\
=f_{u, p} \cdot H C T+(1-H C T),
\end{gathered}
$$

where $f_{u, p}$ is the DEX plasma free fraction (0.175). The calculated $B / P$ s are 0.670 (male) and 0.695 (female), which are similar to in vivo values. The GastroPlus-predicted $B / P$ of 0.88 was slightly greater than experimental values. These findings suggest that limited entry of DEX into RBCs may be attributed to the moderate plasma protein binding.

\section{Discussion}

The purposes of the current study were to assess the tissue distribution of DEX in male and female rats and to develop a PBPK model based on experimental data. Most PBPK studies do not address sex differences, and in silico prediction methods do not take this factor into account. An extensive assessment of the human PK of DEX and betamethasone with a focus on the role of human pregnancy was carried out recently (Ke and Milad, 2019). This included PBPK simulations using the Simcyp Simulator version 17.1 (Certara, Princeton, NJ). Their tissue distribution properties of DEX were likely generated using the same or similar in silico predictions that we have employed. It is not possible to anticipate whether the unusual $K_{p}$ values that we observed in some tissues and the role of the brain P-gp transport would be present in humans. Our study involved dosing by subcutaneous injection instead of oral or intravenous administration because this method offered more reliable absorption, ensured dosing accuracy, produced less animal stress, and enabled us to relate the data to our previous work (Earp et al., 2008; Li et al., 2017).

The distribution of DEX into RBCs is similar to that for prednisolone. Previous studies in rabbits showed that prednisolone RBC concentrations were equal to free plasma concentrations, indicating a similar role of protein binding (Khalafallah and Jusko, 1984). In addition, the endogenous glucocorticoid corticosterone also exhibited a low $B / P$ ratio (0.55) in zebra finches (Taves et al., 2010).

As shown in Table 2, some of the tissues have $K_{p}$ values greater than 1 , indicating higher concentrations of DEX in those tissues than plasma. However, for adipose tissue, the $K_{p}$ value is unexpectedly much smaller than 1. DEX was expected to partition somewhat into adipose tissue due to its moderate lipophilic nature $(\log P=1.83)$. A similar phenomenon was observed for prednisolone in rabbits (Khalafallah and Jusko, 1984) and rats (unpublished). For brain tissue, the $K_{p}$ from subcutaneous infusion data was estimated to be 0.09 , although DEX can readily diffuse through cell membranes and the blood-brain barrier. However, DEX is a substrate for P-glycoprotein transporters (Ueda et al., 1992; Schinkel et al., 1995) and its brain distribution was affected by P-gp in mice as seen with the extremely small $K_{p}$ value calculated from infusion studies (Uchida et al., 2011). Therefore, the efflux of DEX from brain mediated by the highly expressed P-gp in the blood-brain barrier was assumed to occur and was incorporated into our PBPK model. Interestingly, the ratio of the two permeability parameters is 16.6 , similar to the literature- 
Arterial blood

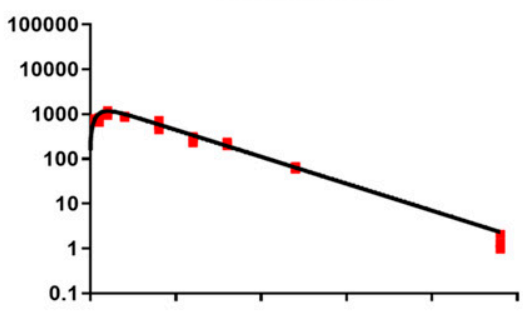

Spleen

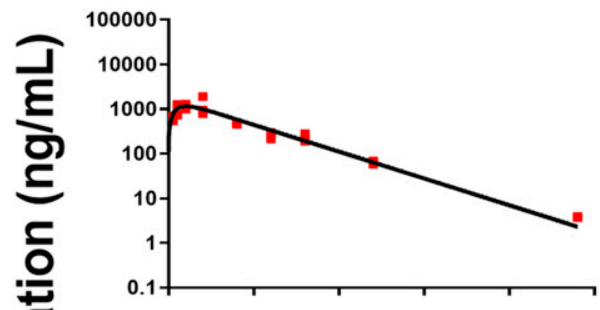

Intestine

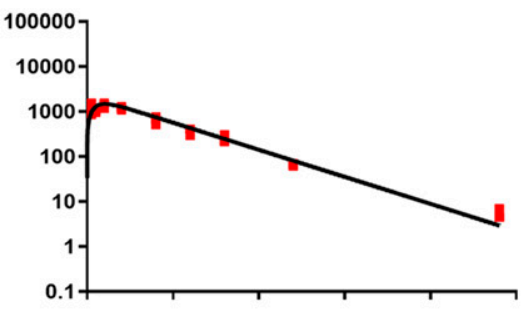

Brain

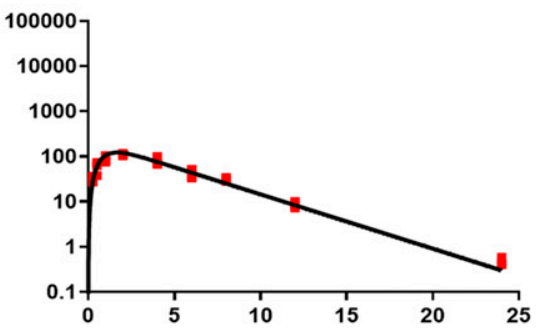

Liver

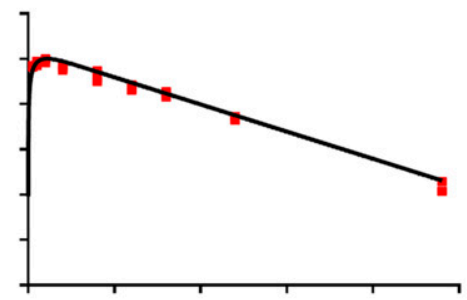

Kidney

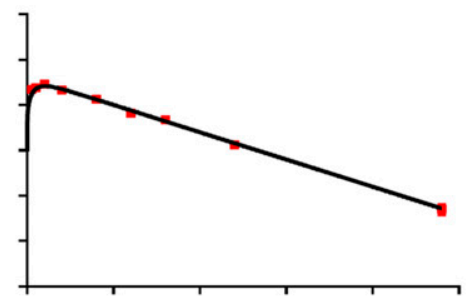

Muscle

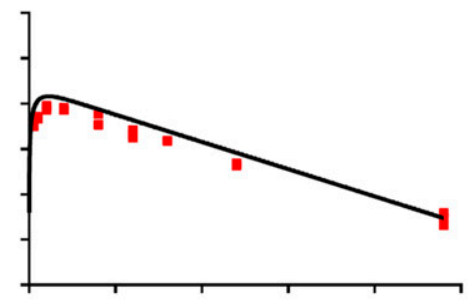

Bone

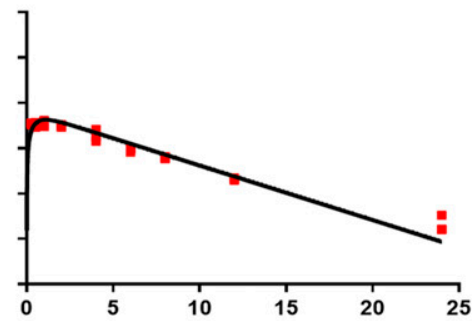

Time after dosing (hour)
Lung

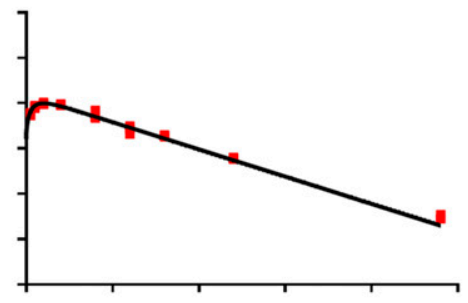

Heart

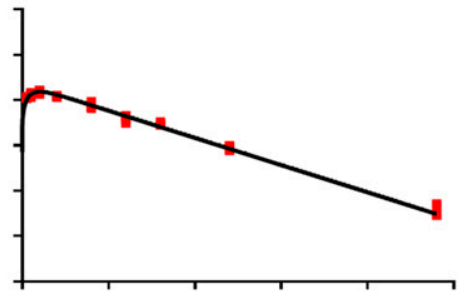

Fat

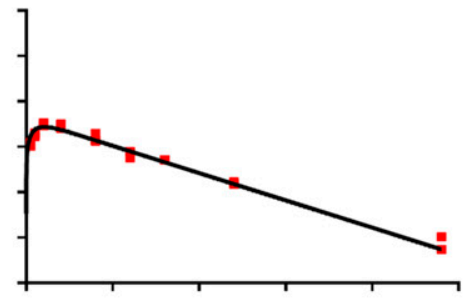

Skin

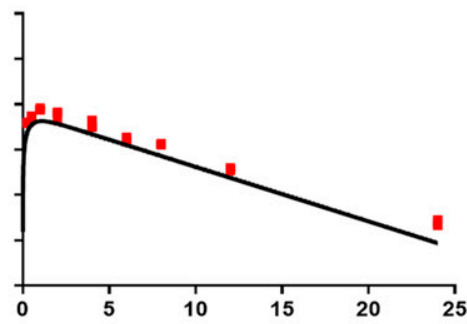

Fig. 3. DEX concentration-time profiles across all tissues after $2.25 \mathrm{mg} / \mathrm{kg}$ s.c. DEX single dosing. Measured DEX concentrations in blood and tissues are indicated by red squares, and black solid lines show the model fitting.

reported flux ratio for DEX (14.7) using LLC-PK1/L-mdr1a cell monolayers (Uchida et al., 2011).

After correction for tissue metabolism, the liver $K_{p}$ was 6.76, which suggests appreciable liver partitioning and binding and is in agreement with liver distribution data for other corticosteroids, such as methylprednisolone (Ayyar et al., 2019b) and prednisolone (unpublished). In silico methods underpredict the liver $K_{p}$ at least 4-fold. These methods mainly assume that tissue distribution was governed by composition differences between tissue and plasma in terms of neutral/phospholipids and water with consideration of binding to albumin and lipoprotein. However, DEX binds to glucocorticoid receptors, which are highly expressed in the liver, and this high affinity binding may help retain DEX in the liver and partially contribute to the liver $K_{p}$. At the same time, evidence for the presence of a glucocorticoid-responsive site in highly purified rat liver plasma membranes was found (Lackner et al., 1998), which was able to mediate active uptake of DEX, possibly contributing to the liver $K_{p}$ and in vivo versus in silico differences. In the remaining tissues, such as intestine, muscle, lung, and heart, DEX partitioning was less compared with liver and kidney. In addition, the $K_{p}$ in skin was 0.40 , indicating modest distribution.

Tissue partitioning parameters obtained from male and female rats were similar in some tissues, differing in others within 1.6-fold. Causes of these differences remained to be determined. By using female $K_{p}$ values and scaling the physiologic parameters for the difference in body sizes, we captured DEX plasma PK profiles in female rats very well (Fig. 4), which further supports our analytical approach.

In silico methods are widely applied in PK modeling to obtain some key parameter values that are difficult to directly measure. However, our 
TABLE 2

Summary of DEX pharmacokinetic parameters

\begin{tabular}{|c|c|c|c|c|c|c|}
\hline Tissue & PBPK & Male infusion ${ }^{a}$ & Female infusion $^{a}$ & Method 1 & Method 2 & Method 3 \\
\hline$K_{p, \text { Lung }}$ & $0.55^{b}$ & $0.50 \pm 0.06$ & $0.69 \pm 0.09$ & 1.4 & 0.8 & 0.59 \\
\hline$K_{p, \text { Brain }}$ & $1.20^{c}$ & $0.06^{c} \pm 0.003$ & $0.10^{c} \pm 0.02$ & 2.53 & 1.16 & 0.85 \\
\hline$K_{p, \text { Heart }}$ & $0.86^{b}$ & $0.84 \pm 0.20$ & $0.85 \pm 0.06$ & 1.09 & 0.68 & 0.48 \\
\hline$K_{p, \text { Intestine }}$ & $0.79^{b}$ & $0.82 \pm 0.14$ & $0.52 \pm 0.04$ & $\mathrm{NA}^{d}$ & $\mathrm{NA}^{d}$ & $\mathrm{NA}^{d}$ \\
\hline$K_{p, \text { Spleen }}$ & $0.64^{b}$ & $0.63 \pm 0.09$ & $0.46 \pm 0.07$ & 0.87 & 0.61 & 0.45 \\
\hline$K_{p, \text { Kidney }}$ & $1.51^{b}$ & $1.24 \pm 0.05$ & $1.05 \pm 0.05$ & 1.21 & 0.72 & 0.50 \\
\hline$K_{p, \text { Muscle }}$ & $0.58^{b}$ & $0.49 \pm 0.05$ & $0.42 \pm 0.04$ & 0.89 & 0.61 & 0.33 \\
\hline$K_{p, \text { Liver }}$ & $6.76^{b}$ & $5.06 \pm 0.56$ & $4.10 \pm 0.56$ & 1.26 & 0.71 & 0.53 \\
\hline$K_{p, \text { Skin }}$ & $0.40^{b}$ & $0.30 \pm 0.08$ & $0.35 \pm 0.03$ & 1.46 & 0.75 & 0.55 \\
\hline$K_{p, \text { Bone }}$ & $0.23^{b}$ & $0.19 \pm 0.03$ & $0.16 \pm 0.01$ & $\mathrm{NA}^{e}$ & $\mathrm{NA}^{e}$ & $\mathrm{NA}^{e}$ \\
\hline$K_{p, F a t}$ & $0.15^{b}$ & $0.16 \pm 0.01$ & $0.10 \pm 0.01$ & 1.37 & 0.83 & 0.83 \\
\hline$K_{p, \text { Rest }}$ & 1 (Fix) & & & & & \\
\hline $\mathrm{ka}$ & \multicolumn{4}{|c|}{ Subcutaneous absorption rate constant $\left(\mathrm{h}^{-1}\right)$} & \multicolumn{2}{|c|}{$1.87^{b}$} \\
\hline$C L_{u, \text { int }}$ & \multicolumn{4}{|c|}{ Hepatic intrinsic clearance $(\mathrm{ml} / \mathrm{h})$} & \multicolumn{2}{|c|}{$404.4^{b}$} \\
\hline$P S_{A L-L}$ & \multicolumn{4}{|c|}{ Brain abluminal to luminal permeability coefficient $(\mathrm{ml} / \mathrm{h})$} & \multicolumn{2}{|c|}{$24.3^{b}$} \\
\hline$P S_{L-A L}$ & \multicolumn{4}{|c|}{ Brain luminal to abluminal permeability coefficient $(\mathrm{ml} / \mathrm{h})$} & \multicolumn{2}{|c|}{$1.46^{b}$} \\
\hline$C L$ & \multirow{2}{*}{\multicolumn{4}{|c|}{ Total plasma clearance (ml/h per kilogram) }} & \multirow{2}{*}{\multicolumn{2}{|c|}{$\begin{array}{c}197.9 \text { (S.D. 16.4, male })^{a} \\
177.6(\text { S.D. } 26.0, \text { female })^{a}\end{array}$}} \\
\hline & & & & & & \\
\hline
\end{tabular}

${ }^{a}$ Calculated based on male and female steady-state infusion study with $n=3$ (S.D. provided).

${ }^{b}$ Estimated parameters with CV\% $<50 \%$ in PBPK model.

${ }^{c}$ Due to active transport, only an apparent $K_{p}$ can be calculated from steady-state data and fixed to 1.2 as found in mice (Uchida et al., 2011).

${ }^{d} \mathrm{NA}$, Not Applicable because tissues associated with the gastrointestinal tract were lumped together.

${ }^{e}$ Not applicable since yellow and red bone marrow values were listed in software.

current results suggest that, although most worked well, differences exist between in vivo and in silico results, especially for the elimination organs. Therefore, caution is needed in adopting in silico values alone; ideally, joint application of in vivo, in silico, and in vitro approaches in PK investigations would increase confidence in results.

Females have slightly smaller clearance values than males (Table 2). This was also found for methylprednisolone in rats (Ayyar et al., 2019a). It is expected that, as DEX is a CYP3A substrate, any sex differences in DEX metabolism should be modest. (Gandhi et al., 2004). No publications for DEX were found, although methylprednisolone exhibits higher clearances in women (Lew et al., 1993).

A potential limitation of our current study involved brain distribution. The P-gp-mediated efflux of DEX was combined with passive diffusion using linear permeability coefficients because of limited information and inability of modeling to discern a low $K_{p}$ from transporter efflux. Active transport often exhibits a maximal capacity and affinity. However,

\section{DEX Plasma PK in Female Rats}

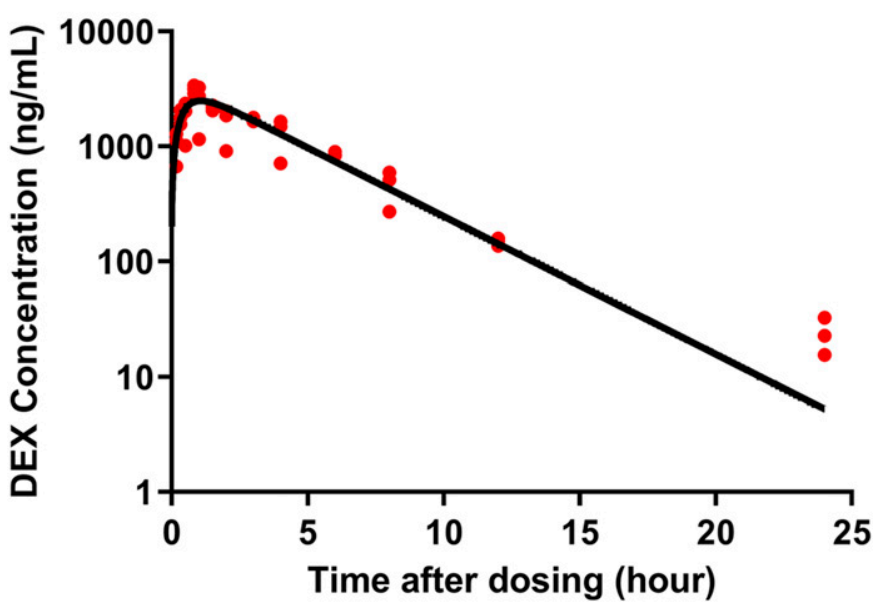

Fig. 4. PBPK model-predicted plasma DEX concentrations after $2.25 \mathrm{mg} / \mathrm{kg}$ s.c. dosing in female rats. Black solid line shows the model prediction, and red dots are measured concentrations. in vivo substrate concentrations are usually low relative to transport mechanisms, leading to expectations of linear brain distribution (Kalvass et al., 2013).

From this investigation on tissue distribution and whole-body PK, it is evident that DEX can easily enter all major tissues and subsequently elicit biologic effects upon binding to ubiquitously expressed glucocorticoid receptors. DEX distribution into nontarget tissues can also the trigger undesired adverse effects. This model may help predict DEX concentrations across different tissues for better understanding of GC pharmacodynamics.

\section{Conclusions}

Our PBPK model describes the experimentally determined tissue and plasma DEX PK profiles in rats well. The apparent P-gp-mediated transport across the blood-brain barrier describes DEX efflux from brain tissue that resulted in a very low measured partition coefficient. Our current model can serve for further investigation of DEX tissue distribution in rats as the PK driving force for receptor-mediated PD effects in various tissues. Slight sex differences were found for DEX tissue distribution and clearance. Knowledge gained in this study may be translatable to other species.

\section{Authorship Contributions}

Participated in research design: Song, Sun, DuBois, Almon, Jusko. Conducted experiments: Song, Sun, DuBois.

Performed data analysis: Song, Sun, DuBois, Almon, Meng, Jusko.

Wrote or contributed to the writing of the manuscript: Song, Sun, DuBois, Jusko.

\section{References}

Ayyar VS, DuBois DC, Nakamura T, Almon RR, and Jusko WJ (2019a) Modeling corticosteroid pharmacokinetics and pharmacodynamics, Part II: sex differences in methylprednisolone pharmacokinetics and corticosterone suppression. J Pharmacol Exp Ther 370:327-336.

Ayyar VS, Song D, DuBois DC, Almon RR, and Jusko WJ (2019b) Modeling corticosteroid pharmacokinetics and pharmacodynamics, Part I: determination and prediction of dexamethasone and methylprednisolone tissue binding in the rat. J Pharmacol Exp Ther 370:318-326. Baschant U, Lane NE, and Tuckermann J (2012) The multiple facets of glucocorticoid action in rheumatoid arthritis. Nat Rev Rheumatol 8:645-655.

Berezhkovskiy LM (2004) Volume of distribution at steady state for a linear pharmacokinetic system with peripheral elimination. J Pharm Sci 93:1628-1640. 
Bernareggi A and Rowland M (1991) Physiologic modeling of cyclosporin kinetics in rat and man. $J$ Pharmacokinet Biopharm 19:21-50.

Bischoff KB, Dedrick RL, and Zaharko DS (1970) Preliminary model for methotrexate pharmacokinetics. J Pharm Sci 59:149-154.

Bischoff KB, Dedrick RL, Zaharko DS, and Longstreth JA (1971) Methotrexate pharmacokinetics. J Pharm Sci 60:1128-1133.

Cato AC, Nestl A, and Mink S (2002) Rapid actions of steroid receptors in cellular signaling pathways. Sci STKE 2002:re9.

Earp JC, Pyszczynski NA, Molano DS, and Jusko WJ (2008) Pharmacokinetics of dexamethasone in a rat model of rheumatoid arthritis. Biopharm Drug Dispos 29:366-372.

Gandhi M, Aweeka F, Greenblatt RM, and Blaschke TF (2004) Sex differences in pharmacokinetics and pharmacodynamics. Annu Rev Pharmacol Toxicol 44:499-523.

Jones H and Rowland-Yeo K (2013) Basic concepts in physiologically based pharmacokinetic modeling in drug discovery and development. CPT Pharmacometrics Syst Pharmacol 2:e63.

Jones HM, Chen Y, Gibson C, Heimbach T, Parrott N, Peters SA, Snoeys J, Upreti VV, Zheng M, and Hall SD (2015) Physiologically based pharmacokinetic modeling in drug discovery and development: a pharmaceutical industry perspective. Clin Pharmacol Ther 97:247-262.

Kadmiel M and Cidlowski JA (2013) Glucocorticoid receptor signaling in health and disease. Trends Pharmacol Sci 34:518-530.

Kalvass JC, Polli JW, Bourdet DL, Feng B, Huang SM, Liu X, Smith QR, Zhang LK, and ZamekGliszczynski MJ; International Transporter Consortium (2013) Why clinical modulation of ef flux transport at the human blood-brain barrier is unlikely: the ITC evidence-based position. Clin Pharmacol Ther 94:80-94.

Ke AB and Milad MA (2019) Evaluation of maternal drug exposure following the administration of antenatal corticosteroids during late pregnancy using physiologically-based pharmacokinetic modeling. Clin Pharmacol Ther 106:164-173.

Khalafallah N and Jusko WJ (1984) Tissue distribution of prednisolone in the rabbit. J Pharmacol Exp Ther 229:719-725.

Lackner C, Daufeldt S, Wildt L, and Alléra A (1998) Glucocorticoid-recognizing and -effector sites in rat liver plasma membrane. Kinetics of corticosterone uptake by isolated membrane vesicles. III. Specificity and stereospecificity. J Steroid Biochem Mol Biol 64:69-82.

Lew KH, Ludwig EA, Milad MA, Donovan K, Middleton E Jr., Ferry JJ, and Jusko WJ (1993) Gender-based effects on methylprednisolone pharmacokinetics and pharmacodynamics. Clin Pharmacol Ther 54:402-414.

Li X, DuBois DC, Song D, Almon RR, Jusko WJ, and Chen X (2017) Modeling combined immunosuppressive and anti-inflammatory effects of dexamethasone and naproxen in rats predicts the steroid-sparing potential of naproxen. Drug Metab Dispos 45:834-845.

Lösel R and Wehling M (2003) Nongenomic actions of steroid hormones. Nat Rev Mol Cell Biol 4: 46-56.

Napier C and Pearce SH (2014) Current and emerging therapies for Addison's disease. Curr Opin Endocrinol Diabetes Obes 21:147-153.

Oakley RH and Cidlowski JA (2011) Cellular processing of the glucocorticoid receptor gene and protein: new mechanisms for generating tissue-specific actions of glucocorticoids. J Biol Chem 286:3177-3184.

Poulin P and Theil FP (2002) Prediction of pharmacokinetics prior to in vivo studies. II. Generic physiologically based pharmacokinetic models of drug disposition. J Pharm Sci 91:1358-1370.
Probst RJ, Lim JM, Bird DN, Pole GL, Sato AK, and Claybaugh JR (2006) Gender differences in the blood volume of conscious Sprague-Dawley rats. J Am Assoc Lab Anim Sci 45:49-52.

Rhen T and Cidlowski JA (2005) Antiinflammatory action of glucocorticoids--new mechanisms for old drugs. $N$ Engl J Med 353:1711-1723.

Rodgers T and Rowland M (2006) Physiologically based pharmacokinetic modelling 2: predicting the tissue distribution of acids, very weak bases, neutrals and zwitterions. J Pharm Sci 95 : $1238-1257$.

Sager JE, Yu J, Ragueneau-Majlessi I, and Isoherranen N (2015) Physiologically based pharmacokinetic (PBPK) modeling and simulation approaches: a systematic review of published models, applications, and model verification. Drug Metab Dispos 43:1823-1837.

Samtani MN and Jusko WJ (2005) Comparison of dexamethasone pharmacokinetics in female rats after intravenous and intramuscular administration. Biopharm Drug Dispos 26:85-91.

Samtani MN, Pyszczynski NA, Dubois DC, Almon RR, and Jusko WJ (2006) Modeling glucocorticoid-mediated fetal lung maturation: I. Temporal patterns of corticosteroids in rat pregnancy. J Pharmacol Exp Ther 317:117-126.

Schinkel AH, Wagenaar E, van Deemter L, Mol CA, and Borst P (1995) Absence of the mdr1 P-Glycoprotein in mice affects tissue distribution and pharmacokinetics of dexamethasone, digoxin, and cyclosporin A. J Clin Invest 96:1698-1705.

Shah DK and Betts AM (2012) Towards a platform PBPK model to characterize the plasma and tissue disposition of monoclonal antibodies in preclinical species and human. $J$ Pharmacokinet Pharmacodyn 39:67-86.

Song D, DuBois DC, Almon RR, and Jusko WJ (2018) Modeling sex differences in antiinflammatory effects of dexamethasone in arthritic rats. Pharm Res 35:203.

Taves MD, Schmidt KL, Ruhr IM, Kapusta K, Prior NH, and Soma KK (2010) Steroid concentrations in plasma, whole blood and brain: effects of saline perfusion to remove blood contamination from brain. PLoS One 5:e15727.

Tomlinson ES, Maggs JL, Park BK, and Back DJ (1997) Dexamethasone metabolism in vitro: species differences. J Steroid Biochem Mol Biol 62:345-352.

Uchida Y, Ohtsuki S, Kamiie J, and Terasaki T (2011) Blood-brain barrier (BBB) pharmacoproteomics: reconstruction of in vivo brain distribution of $11 \mathrm{P}$-glycoprotein substrates based on the BBB transporter protein concentration, in vitro intrinsic transport activity, and unbound fraction in plasma and brain in mice. $J$ Pharmacol Exp Ther 339:579-588.

Ueda K, Okamura N, Hirai M, Tanigawara Y, Saeki T, Kioka N, Komano T, and Hori R (1992) Human P-glycoprotein transports cortisol, aldosterone, and dexamethasone, but not progesterone. J Biol Chem 267:24248-24252.

Volin P (1995) High-performance liquid chromatographic analysis of corticosteroids. J Chromatogr B Biomed Appl 671:319-340.

Zhuang X and Lu C (2016) PBPK modeling and simulation in drug research and development. Acta Pharm Sin B 6:430-440.

Address correspondence to: Dr. William J. Jusko, Department of Pharmaceutical Sciences, School of Pharmacy and Pharmaceutical Sciences, State University of New York at Buffalo, 404 Pharmacy Bldg., Buffalo, NY 14214-8033. E-mail: wjjusko@buffalo.edu 